\title{
Challenges and Successful Management of Chronic Post Dural Puncture Headache Using Epidural Blood Patch in Low-Income Setting: Case Report
}

\author{
Samuel C 0jiakor ${ }^{1,2}$, Afam B Obidike ${ }^{2}$, Kenneth N Okeke ${ }^{2}$, George U Eleje ${ }^{3,4 *}$, Chima P Umobi ${ }^{5}$ \\ and Chiamaka 0 Okpalakunne ${ }^{5}$ \\ ${ }^{1}$ Department of Anaesthesiology, Nnamdi Azikiwe University, Awka, Anambra State, Nigeria \\ ${ }^{2}$ Department of Anaesthesiology, Nnamdi Azikiwe University Teaching Hospital, Nnewi, Anambra State, Nigeria \\ ${ }^{3}$ Depatment of Obstetrics and Gynaecology, Nnamdi Azikiwe University, Awka, Anambra State, Nigeria \\ ${ }^{4}$ Depatment of Obstetrics and Gynaecology, Nnamdi Azikiwe University Teaching Hospital, Nnewi, Anambra State, Nigeria \\ ${ }^{5}$ Department of Nursing Services, Nnamdi Azikiwe University Teaching Hospital, Nnewi, Anambra State, Nigeria
}

*Corresponding author: George Uchenna Eleje, Effective Care Research Unit, Department of Obstetrics and Gynecology, Nnamdi Azikiwe University, Awka, Nigeria/ Department of Obstetrics and Gynecology, Nnamdi Azikiwe University Teaching Hospital, PMB

5025, Nnewi, Nigeria

\section{ARTICLE INFO}

Received: 杫 November 16, 2020

Published: 豐 November 23, 2020

Citation: Samuel C Ojiakor, Afam B Obidike, Kenneth N Okeke, George U Eleje, Chima P Umobi, Chiamaka O Okpalakunne. Challenges and Successful Management of Chronic Post Dural Puncture Headache Using Epidural Blood Patch in Low-Income Setting: Case Report. Biomed J Sci \& Tech Res 32(1)-2020. BJSTR. MS.ID.005195.

Keywords: Blood Patch; Epidural; Lowincome; Post dural puncture headache

Abbreviations: CSF: Cerebro Spinal Fluid; CT: Computed Tomography; PDPH: Post Dural Puncture Headache

\section{ABSTRACT}

Background: Post Dural Puncture Headache (PDPH) was first described in 1898 by August Bier as a severe headache developed as a complication of dural perforation. This experience was reported to be worse on standing or sitting and temporarily relieved on lying in supine position. However, PDPH can persist requiring the use of epidural blood patch for effective management.

Objectives: The aim of this article was to report the challenges and successful of management of PDPH using epidural blood patch in a low-income setting.

Case Presentations: We report three cases of severe throbbing headache localized in the frontal area of the head and associated with stiff neck that presented to our facility in Nnamdi Azikiwe University Teaching Hospital, Nnewi, Nigeria through our pain clinic following history of spinal anaesthesia carried out in a private health centre. Various measures including several types of analgesics was said to have been used in the primary centre without any significant relief. Epidural blood patch was performed after the diagnosis of PDPH was made and symptoms resolved completely after 30 minutes to 1 hour of administration of the blood patch.

Conclusion: We demonstrated the effectiveness of epidural blood patch technique in the management of PDPH.

\section{Introduction}

Post Dural Puncture Headache (PDPH) is one of the most debilitating complications of dural puncture that is characterized by a constant headache often localized at frontal and occipital area. The symptom is worse in sitting or standing lasting few hours, days or months [1]. It is an important cause of morbidity in modern day anaesthesia and pain medicine capable of placing an increased cost of hospitalization by extending the length of hospital stay [2]. PDPH is usually a self-limiting process with incidence ranging between
30 - 50\% following diagnostic puncture, $0.16-3.6 \%$ after spinal anaesthesia and up to $80 \%$ following accidental dural puncture during epidural analgesia placement in labour [3,4]. About 75\% of these cases recover spontaneously within 7 days and nearly $90 \%$ resolves within 6 weeks [1-5]. However, a small proportion could persist for several months [6,7]. Several measures have been adopted to prevent and treat PDPH resulting in varying degrees of success [3,6-8]. Among these measures, epidural blood patch remains the most effective intervention $[6,7,9]$. 


\section{Cases}

\section{Case 1}

A 30-year old woman presented to our pain clinic in Nnamdi Azikiwe University Teaching Hospital, Nnewi, Nigeria with complaint of severe throbbing headache of 3 months developed 2 days after spinal anaesthesia for caesarean section. The headache was said to be localized in the frontal region associated with difficulty in gazing, nausea and worse in standing and walking but was temporarily relieved on lying on supine position. There was no history or pre-existing chronic medical illness. Medical records regarding the conduct of Anaesthesia and Caesarean section could not be gotten, and we have to rely on the information from the patient because the case was carried out in a private health facility. Physical examination and Radiological investigation revealed intact neurological system while other causes of headache were also excluded. Post dural puncture headache was suspected, and patient was subsequently admitted. The patient was counseled for epidural blood patch. The procedure was performed by 2 operators following aseptic protocols.

The patient was positioned sitting on an operating table while legs rests on a stool, thereafter the back is cleaned with iodine and the choice intervertebral space was identified and most preferably the space near the site of the previous puncture. The $2 \mathrm{mls}$ of plain lidocaine was used to infiltrate the choice space followed by the insertion of the tuohy needle and the correct placement into the epidural space was confirmed through loss of resistance to air, thereafter about $15-20 \mathrm{ml}$ of patients' blood collected from the ante-cubital region by the assistant was injected into the epidural space until the patient feels fullness in the spine, the needle removed and patient is placed in supine position for about $1-2$ hours, and subsequently discharged. She was followed up through the clinic visits up to 6 weeks without any further complaints.

\section{Case 2}

We report a case of 44 years old male who presented to our pain clinic in Nnamdi Azikiwe University Teaching Hospital, Nnewi, Nigeria with 5 months history of severe headache which he developed 3 days after spinal anaesthesia for an orthopaedic procedure carried out in a private orthopaedic hospital. The headache was persistently frontal and worsened on standing. There was no history of trauma to the head, no nausea, no neck stiffness or hearing symptom. Patient further revealed that the surgeon performed the spinal anaesthesia himself. He was said to have taken several medications without appreciable relief. An examination of the systems shows that they were grossly normal while Computed Tomography (CT) of the brain and spine were normal. We suspected post dural puncture and subsequently we counseled the patient for epidural blood patch and informed consent was obtained. Epidural blood patch was performed, and the symptoms ceased immediately and completely. The patient was thereafter discharged and followed up through the pain clinic and the symptoms never reoccurred after 3 months of clinic visit.

\section{Case 3}

We report a case of 38 years old woman who was admitted to Nnamdi Azikiwe University Teaching Hospital, Nnewi, Nigeria through the pain clinic on account of 8 months history of headache localized as the frontal occipital region, non-pulsatile aggravated on sitting and standing. There was history of nausea, tinnitus, and neck rigidity. There was history of spinal anaesthesia for emergency caesarean section carried out in a private hospital in Cameroon from where she returned due to worsening condition.

Examination yielded no neurological deficit. Cranial and spine CT were essentially normal. A differential diagnosis of post dural puncture headache was made and worked up for epidural blood patch. She had several medications including antibiotics, strong analgesics such as opioids without significant change. Consent was obtained for epidural blood patch after 72 hours of aggressive treatment with antibiotics and morphine. After consent was obtained, the patient was positioned sitting on the couch with legs resting on a stool. The back and the antecubital area was cleaned aseptically thereafter the choice intervertebral space near the site of previous puncture was infiltrated with $2 \mathrm{mls}$ of $1 \%$ plain lidocaine then the epidural space was accessed using size 18G tuohy needle and confirmed through loss of resistance to air. An assistant collected about $25 \mathrm{mls}$ of blood from the cleaned antecubital area, the blood is subsequently injected into the epidural space until the patient feels pressure at the back. The patient was made to lie prone for about 30 minutes to 1 hour and then stand for reassessment. It was noted that symptoms had resolved completely just after the epidural blood patch, and she was observed for 2 more days and was subsequently discharged without any further complaints. She was followed up for 3 months in the clinic thereafter discharged from pain clinic services.

\section{Discussion}

Since the first description of headache associated with dural puncture by Bier in 1898, PDPH has continued to be a significant cause of morbidity in anaesthesia and Therefore, pain medicine practice should not be taken lightly [3,5]. It has been reported that where symptoms are allowed to persist have led to subdural haematoma or even death in worst case scenario especially in patients with vulnerable nerves such as diabetes mellitus [10]. According to the international headache society, PDPH has been described as headache occurring up to 7 days after dural puncture and expected to resolve spontaneously within 14 days [11]. The import of this classification by the headache society was that punctured dura are expected to seal off inflammatory and haemostatic mechanism within the time frame. However, there are a number of cases reported in literature where headaches resulting from dural puncture fails to close persisting for several months 
$[6,7,11]$. We also reported three cases in this article of PDPH lasting 3 months and above.

The exact pathogenesis of PDPH is not fully known but some authors have hypothesized as follows, the reduction in the CSF volume and pressure leads to the loss of buoyancy of the intracranial contents which allows sagging of the brain and the supporting structures so that when the patient assumes an upright position, the headache occurs as a result of direct traction of pain sensitive structures from the descending cranial contents. Another theory is based on Moroe-Kelly doctrine which states that the skull is a rigid vault containing CSF, blood and brain, a reduction in any of the contents of the skull will lead to a compensatory increase in others targeted at maintaining the intracranial pressure. The continuous loss of CSF following a rent in the dura will cause a compensatory veno-dilatation with a consequent effect of hypotension and headache $[3,9]$.

Many factors contribute to the development of PDPH, for instance, there is a direct correlation between the incidence of PDPH and the size and shape of spinal needles used for performance of neuroaxial block [12]. We reviewed several literatures and found that the incidence of PDPH rises significantly with the use of largebore spinal needles [12-14]. A study conducted in Jos, Nigeria [15] reported a prevalence of PDPH as high as $22.3 \%$ compared with another study with lower prevalence of $8.3 \%$ [16]. The Jos study noted that large-bore spinal needles used in their study were a major contributor to the observed prevalence.

The shape of needle has also been identified as one of the predisposing factors to PDPH. Quinke spinal needles which is regarded as a traumatic or cutting needle have be reported to be associated with higher incidence of PDPH $[14,17,18]$. Another study by Mohammed, et al. [17] revealed how needle shape contributed to higher incidence of PDPH. The authors of Mohammed et al study reported that no incidence of PDPH was recorded in their study when they compared small sized (27G) Quinke with whitacre needles. This thus suggests that size rather than shape is the major culprit to PDPH development.

The incidence of $\mathrm{PDPH}$ is inversely proportional to the experience or expertise of the neuraxial block operator. This was demonstrated in a recent study [15] where several incorrect positioning of the needle bevel significantly contributed to the high incidence of PDPH recorded in that study. Another study conducted in South Africa [18] among Primary Care Physicians with regard to performance of spinal anaesthesia for patients undergoing various surgical procedures noted a high incidence of PDPH as well lack of skill required to performing epidural blood patch, for the treatment of PDPH. They concluded that there was need for special training and skill acquisition for these practitioners so as to mitigate the debilitating effect of PDPH. Our experience with the 3 cases reported in this article was similar to that above [19] in that spinal anaesthesia was said to be performed by untrained operators in the private clinics.

Apart from already listed factors, female gender, pregnancy and past history of headache may also predispose patients to developing PDPH [19]. Christopher and colleagues [20] systematically reviewed several articles and found that female gender has a higher risk of developing PDPH compared with males but the mechanism supporting their claim was not strong. Our present case series reported both male and female patients with no clear distinction in terms of evolution and progression of the symptoms of, PDPH. The diagnosis of PDPH [21] is largely based on the clinical history and presentation after other differentials have been excluded. These includes hypoglycaemia, meningitis, encephalitis, dehydration, caffeine withdrawal syndrome, migrane, cerebral vein thrombosis, cerebral infection, sub-dural haematoma, benign intracranial hypertension, pneumoencephalus, tensional headache, space occupying lesion and other neurological disorders [22].

Most PDPH would resolve spontaneously $[3,11,23]$ but some may persist for several months [6,7]. Several measures have been adopted in the management of PDPH including conservative measures and interventional approach. The conservative measures involves bed rest with patient lying in supine position, generous hydration and drugs $[3,8]$. Drugs such as paracetamol, sumatriptan, caffeine and opioids with other measures have been used offering varying degree of success especially in mild cases. In most severe cases, the conservative methods offer no relief $[3,6]$. The interventional approach involves epidural saline and epidural blood patch $[6,7,12]$. The epidural saline entails the placement of epidural needle and injection of saline or colloids into the epidural space. Some relief has been reported but the overall effectiveness was limited [5]. Epidural blood patch involves placement of epidural needle into the epidural space near the site of previous puncture and thereafter injection of about $15-20 \mathrm{mls}$ of autologous blood through the epidural needle until the symptom disappears. Among the several measures so listed, epidural blood patch is the most effective [3,6,7,24].

Based on the diagnostic and management approaches observed in the several articles reviewed $[3,6,7,15,16,24,25]$ we decided to carry out detailed radiological investigation to rule out other causes of headache and thereafter performed epidural blood patch which resulted in complete resolution of the headache. The patients were followed up for about 8 weeks through the pain clinic to validate the effectiveness of the treatment techniques. The patients were subsequently discharged from the pain management services [2628]. 


\section{Conclusion}

We found epidural blood patch as a veritable technique for the treatment of post dural puncture headache and we equally advocated the engagement of Anaesthesiologist or at least a specially trained neuraxial block operator to flatten the incidence of PDPH and consequently instigating its devastating effect in low income setting. Despite the challenges, success was achieved.

\section{Acknowledgments}

We thank persons who assisted with the manuscript preparation.

\section{References}

1. Claisir R (2006) Post dural puncture headache. Curr Opin Anesthesiol 19(3): 249-253.

2. Reynolds F (1993) Dural Puncture Headache. BMJ 3906(6882): 874876.

3. Turnbill DK, Shephered DB (2003) Post dural puncture headache: Pathogenesis, prevention and treatment. BMJ 91(5): 718-729.

4. Gisore E, Mingaya V, Sharif I (2010) Incidence of post dural puncture headache following caesarean section under spinal anaesthesia at the AgaKhan University Hospital, Nairobi. East African Medical Journal 87(6): 227-230.

5. Baraz R, Collin RE (2005) The management of accidental dural puncture during labour epidural analgesia.A survey of UK practice. Anaesthesia 60(7): 675-679.

6. Mumba JM (2018) Epidural blood patch for an eight moth history of Post dural puncture headache case reports. Journal of Anaesthesia\& Critical Care Open Access 10(3): 113-115.

7. Bambosa FT (2011) Prevalence inexperume spinal block operator. Post dural puncture headache with seven months duration: Case report. Rev Bras Anestesiol 61(3): 355-359.

8. Sechzer PH (1979) Post Spinal anaesthesia headache treated with caffeine. Evaluation with Demand method Part 2. CurrTher Res 26: 440448.

9. Blew P G (2012) Essentials of Pain Medicine - $3^{\text {rd }}$ Edn. Can J Anesth 59: 1002-1004.

10. Zeiden A, Larhet O, Maaliki H, Baraka A (2006) Does post dural puncture headache left untreated lead to subdural heamatoma? Case report and review of literature. Int J Obstetrics Anaesthesia 15(1): 50-58.

11. (2018) Headache Classification Committee of the International Headache Society. The International Classification of Headache Disorders Cephalagia 38 (1): 1-211.

12. Gogarten W, Van Aken H (200) A century of Regional analgesia in Obstetrics. Analg 91(4): 273-275.

13. Mohammed AD, Ayuuba R, Salisu I, Nagoma AU, Oloolabi LF, et al. (2017) An analysis of post dural puncture headache in obstretric patients.A study from Kano, Nigeria. Trop J Obstet Gynecol 34(1): 16-20.
14. Gisore E, Mingaya V, Sharif I (2010) Incidence of post dural puncture headache following caesarean section under spinal anaesthesia at the AgaKhan University Hospital, Nairobi. East African Medical Journal 87(6): 227-230.

15. Nuhu SI, Embu HY, Sherinbe I (2017) Prevalence of post dural puncture headache among caesarean section patients in North Central Nigeria. Kanem Journal of Medical Sciences 1: 47-52.

16. Nafiu OO, Salam RA, Elegbe EO (2007) Post dural puncture headache in Obstetric patient: Experience from most African Teaching Hospital. Int J Obstet Anaesth 16(1): 4-7.

17. Mahmond GM (2015) Post dural puncture headache after spinal anesthesia for caesarean section. A comparison of 27G Quincke and Whitaere spinal needle and paramedian approaches. J Med Sci 15(1): 44-49.

18. Camole OB, Ogunbanjo GA (2015) Post dural puncture headache: Evidence -based review of primary care. S Afr Fam Pract 57(4): 241246.

19. Jabbari A, AlijanPour E, Mir M, Barihashen N, Rebecca SM, et al. (2013) Post spinal puncture headache, an old problem and new concept. Review of articles about predisposing factors. Caspian J Intern Med 4(1): 595-602.

20. Christopher LWU, Andrew JR, Seth RC, Robert RM, Gewvive EC, et al. (2006) Gender and Post Dural Puncture Headache. Anesthesiology 105: 613-618.

21. Muhammed SK, Ghwulam NM, Safia MS, Magsood AS (2007) Post dural puncture headache in obstetrics. A comparative study using whitacre, 27G and Quincke, 27G accoles. Med Channel 91: 299-300.

22. Evans RW, Armon C, Frohman EM, Goodmy DS (2000) Assessment, Prevention of Post Dural Puncture headacheSubcommittee of the American Academy of Neurology. Neurology 55(7): 909-911.

23. Nguyen DY, Walters RR (2014) Standardizing Management of Post Dural Puncture Headache in Obstetric Patients.A literature review. Open Journal of Anesthesiology 4(10): 244-253.

24. Ofoegbu VA, Mato CN (2004) Epidural blood patch for Post dural puncture headache. A handy ally Niger J Med 13(1): 59-61.

25. Kassa AA, BeyenTK (2014) Prevalence and Severity of Postdural puncture headache (PDPH) and associated factors after spinal anaesthesia among patients in University of Gondar Referral and Teaching Hospital, Gondar, North West, Ethiopia. Analg Resusc Curr Res 4: 3.

26. Fyne Face-Ogan S, Mato CN, Odagme MT (2006) Post dural puncture headache following casesarean section in Nigeria paturuints. A comparison of two spinal needles. Niger Postgrad Med J 13(3): 200-202.

27. Ghaleb A, Khorasoni A, Mangar D (2012) Post dural puncture headache. Int J General Med 5: 45-51.

28. Adekola 00, Desallu I, Adekunle MO, Asiyanbi GE, Iruhe I (2015) Complication and Outermes following central neuraxialanaesthesia in Sub-Saharan Tertiary Hospital. The legal implication. Egyptian Journal of Anesthesia 31(2): 189-195. 
ISSN: 2574-1241

DOI: 10.26717/BJSTR.2020.32.005195

George U Eleje. Biomed J Sci \& Tech Res

(C) (P) This work is licensed under Creative

Submission Link: https://biomedres.us/submit-manuscript.php

$\begin{array}{ll}\text { BIOMEDICAL } & \text { Assets of Publishing with us } \\ \text { RESEARCHES } & \text { - Global archiving of articles } \\ \text { - Immediate, unrestricted online access } & \text { - Rigorous Peer Review Process } \\ & \text { - Authors Retain Copyrights } \\ & \end{array}$

